D.O.I.: $10.3895 / \mathrm{S} 1808-04482006000300007$

\title{
COMPETÊNCIAS REQUERIDAS PELOS GESTORES DE INSTITUIÇÕES DE ENSINO SUPERIOR PRIVADAS: UM ESTUDO EM CURITIBA E REGIÃO METROPOLITANA
}

\section{THE MAIN COMPETENCIES NECESSARY FOR A MANAGER OF A PRIVATE INSTITUTION}

\author{
Murilo M. de Andrade ${ }^{1}$;Faimara R. Strauhs ${ }^{2}$ \\ ${ }^{1}$ Faculdade Educacional de Araucária - FACEAR - Araucária - Brasil murilo@,facear.edu.br \\ ${ }^{2}$ Federal Technological University of Paraná - UTFPR - Curitiba - Brasil \\ faimara@lit.citec.cefetpr.br
}

\begin{abstract}
Resumo
O presente trabalho tem por objetivo maior tratar das competências requeridas pelos gestores de Instituições de Ensino Superior Privadas - IES, um estudo em Curitiba e sua Região Metropolitana. A investigação foi do tipo exploratória, bibliográfica e descritiva, com características de pesquisa qualitativa e quantitativa. Também foi utilizado o método survey, muito comum nas ciências sociais. Na última década o cenário do ensino superior no Brasil foi bastante alterado, afetando sobremaneira as instituições existentes e as que ingressaram neste segmento. A expansão acelerada deste nível de ensino gerou maior concorrência. Diante desta realidade fez-se necessário buscar modelos inovadores de gestão para enfrentar estes novos tempos, e a importância do dirigente principal da IES é fundamental para se obter um modelo de gestão eficiente e adaptado ao novo panorama. $O$ estudo pesquisou fundamentalmente o assunto competências, tanto organizacional como dos administradores, para poder definir quais as competências mais importantes para um gestor de IES privada. Os dados coletados são apresentados de acordo com os objetivos propostos no início da pesquisa e as conclusões obtidas permitem identificar qual o perfil atual dos gestores de IES privadas de Curitiba e região metropolitana e também as competências requeridas para que um gestor de IES privada seja eficaz no desenvolvimento do cargo que ele ocupa.
\end{abstract}

Palavras-chave: educação superior; gestão; gestor; competências; instituições de ensino superior.

\section{Introdução}

O ensino superior brasileiro, especialmente o de graduação, vive uma fase de grande crescimento. Nos últimos anos houve um aumento considerável no número de Instituições deste nível de ensino, sobretudo privadas. Segundo dados do Censo da Educação Superior, realizado pelo INEP - Instituto Nacional de Estudos e Pesquisas Educacionais, em 1997 havia 211 Instituições de Ensino Superior - IES públicas e 689 particulares, resultando em um total de 900 IES. Em 2003, o 
número de instituições públicas havia caído para 207 e o número de IES privadas subido para 1.652, somando 1.859 instituições ao todo, um aumento de 106,5\%. O número de vagas ofertadas pelas IES também cresceu em torno de 186\%, subindo de 699.198 vagas em 1997 para 2.002 .685 em 2003 (BRASIL, 2004).

Em virtude do aumento do número de IES, e de vagas oferecidas, acirrou-se a disputa entre as instituições privadas pelos candidatos ao preenchimento destas vagas, já que a principal fonte de receitas provém da cobrança de mensalidades pelos serviços educacionais prestados. De acordo com os dados do Censo da Educação Superior de 2003, realizado pelo INEP, o número de vagas ociosas, neste mesmo ano, nas IES privadas foi de aproximadamente 42\% (BRASIL, 2004). Além da ociosidade, as IES enfrentam ainda a desistência de alunos, o trancamento de cursos, as saídas por transferências para outras instituições, a inadimplência no pagamento das mensalidades entre outros problemas.

De acordo com Rocha e Granemann (2003), o acirramento da competição é evidente e as IES privadas precisam considerar os princípios gerenciais modernos, valorizando o planejamento estratégico, a definição de metas, o orçamento anual e a administração de projetos, ou seja, implantando medidas que direcionem a organização na consecução dos seus objetivos estratégicos.

No processo de busca de novas técnicas e teorias administrativas para as IES, torna-se de fundamental importância o papel do gestor da IES, pois ele, junto com seus técnicos, é o principal envolvido na definição da missão, dos objetivos e das metas da instituição, bem como na eficiência da implementação das estratégias institucionais, assegurando uma gestão de qualidade (TACHISAWA; ANDRADE, 2002).

Neste cenário, o trabalho ora apresentado, resultado de uma dissertação de mestrado, pretende propor, após pesquisa teórica e empírica realizada em Curitiba e sua região metropolitana, quais as competências requeridas por gestores de IES privada, que viabilizem a implantação e o desenvolvimento de modelos inovadores de gestão, com vistas a um mercado em expansão, garantindo a possibilidade de competição atual e futura nas IES.

\section{Gestão de competências - variáveis interdependentes nas IES}

É fato que a expansão da rede privada de ensino tem sido muito superior à federal. Conforme pesquisa, na região metropolitana de Curitiba em 2002 foram 1,3 vestibulandos por vaga no ensino superior privado. Desta forma, com a grande competição entre as instituições de ensino privadas, a gestão é fundamental para alcançar as metas propostas.

São necessárias novas práticas administrativas, pois a mudança é a única constante nesse processo. As práticas organizacionais mais citadas na literatura apontam para: ênfases nos 
processos, planejamento estratégico, equipes organizacionais, valorização dos trabalhadores do conhecimento, aprendizado sistêmico, maior investimento em pesquisa e desenvolvimento, responsabilidade social entre outras práticas.

A atual realidade do ensino superior demonstra que o antigo modelo de gestão das IES precisa ser revisto para se adequar ao novo modelo educacional. A busca pela qualidade na IES deve ser uma constante e o processo de gestão da qualidade está intimamente ligado à sua gestão estratégica, envolvendo todos os membros da organização. Sendo assim, é função dos gestores da Instituição traçar os objetivos e fixar as metas de qualidade (KOTLER; FOX, 1994). Para tanto, é necessário buscar modelos inovadores de gestão, baseados na nova realidade do mercado e visando a qualidade na prestação dos serviços educacionais, equilibrando receitas e despesas para atingir os objetivos pretendidos.

A maioria das instituições particulares de ensino superior é de origem familiar, filantrópica ou confessional e a sua administração é feita por gestores que não possuem as competências requeridas para o cargo que ocupam. Grande parte destes dirigentes veio da docência, ou são pessoas que possuem formação superior em outras áreas, como economia, contabilidade, engenharia, direito e outras. Esta deficiência é comum tanto em instituições de ensino públicas como também em privadas.

Nas públicas os cargos de gestão são escolhidos mediante eleições ou indicações políticas e nas particulares são as famílias proprietárias que administram estas organizações. Nas privadas fundacionais de entidades religiosas e filantrópicas a gestão é feita pelos membros destas organizações, como padres e pastores.

O problema reside no fato de que são poucos os que possuem competência na área específica de Gestão de IES. Isto leva a que, por vezes, o bom desempenho obtido na área técnica de atuação de origem não se repita quando se trata de realizar funções de gestão universitária. Não obstante a grande experiência, isto não é suficiente. Há técnicas peculiares desta área que devem ser conhecidas.

A gestão de IES deixou de ser um processo simples, são muitos os fatores envolvidos nos segmentos, desde a questão da entrada do aluno pelo vestibular até a gestão de pessoal da própria instituição, ou seja, o gestor necessita de algumas competências fundamentais para o desempenho de suas funções.

No âmbito deste trabalho, competência, de acordo com Durand (1998, p.3), é um "Conjunto de conhecimentos, habilidades e atitudes interdependentes e necessárias à consecução de determinados propósitos."

Competências individuais importantes para os gestores são: inovação, determinação, liderança individual e em equipe, ter um bom networking, criatividade, flexibilidade, iniciativa, 
autocontrole, integridade, persistência, sensibilidade, planejamento, apresentação escrita e oral, negociação, correr riscos, poder de decisão, conhecimento profissional e técnico, energia, interesses diversos, iniciativa, tolerância ao stress, adaptabilidade (WOOD, 1997).

\section{A pesquisa: do entorno aos resultados}

A pesquisa foi exploratória, bibliográfica e descritiva, tendo como objetivo principal a investigação das competências requeridas para o gestor de IES privada. Caracterizou-se, ainda, como quali-quantitativa, segundo os critérios de Triviños (1995). De acordo com o problema de pesquisa proposto foi utilizado o método do tipo survey, que é bastante conhecido nas ciências sociais. O formato do survey permite elaboração clara e rigorosa de um modelo lógico, clarificando o sistema determinístico de causa e efeito.

A coleta de dados da pesquisa foi realizada no município de Curitiba e sua Região Metropolitana - RM e para tanto foram utilizados questionários diferenciados, aplicados via Internet, para gestores principais e para seus subordinados diretos.

Até fevereiro de 2005, dos vinte e seis municípios que compõe a Região Metropolitana de Curitiba, apenas oito deles possuíam Instituições de Ensino Superior credenciadas pelo Ministério da Educação: Araucária, Campina Grande do Sul, Campo Largo, Colombo, Curitiba, Lapa, Pinhais e São José dos Pinhais. Existiam 51 IES privadas em Curitiba e na RM em dados de fevereiro de 2005. Contudo, foi constatado que duas das IES não existem, ou seja, só há o ato legal de credenciamento da instituição, porém ainda não há nenhum curso em funcionamento. Em virtude dessa condição, tais instituições foram excluídas da pesquisa, bem como em outros oito casos em que as instituições pertencem à mesma mantenedora e elas funcionam sob uma mesma administração. E a última excluída do universo pesquisado foi a faculdade na qual o autor deste trabalho é diretor geral, o que inviabiliza a coleta de dados nesta IES. Sendo assim, o universo das instituições pesquisadas foi reduzido a 40 IES.

Das quarenta IES pesquisadas obteve-se resposta de vinte e um gestores principais, o que dá uma taxa de 52,5\% de retorno dos diretores. Já quanto aos subordinados obteve-se resposta de vinte e nove das quarenta IES pesquisadas, totalizando $72,5 \%$ de taxa de retorno. Na Tabela 1 observa-se que quanto ao número total de IES respondentes, foram trinta e duas instituições, perfazendo $80 \%$ de retorno. 
Tabela 1 - Número de ies respondentes à pesquisa

\begin{tabular}{|c|c|c|c|c|c|c|c|}
\hline \multicolumn{2}{|c|}{$\begin{array}{l}\text { NÚMERO DE } \\
\text { IES } \\
\text { PESQUISADAS }\end{array}$} & \multicolumn{2}{|c|}{$\begin{array}{l}\text { NÚMERO DE } \\
\text { DIRETORES QUE } \\
\text { RESPONDERAM } \\
\end{array}$} & \multicolumn{2}{|c|}{$\begin{array}{c}\text { NÚMERO DE IES } \\
\text { ONDE HOUVE RESPOSTA DOS } \\
\text { SUBORDINADOS }\end{array}$} & \multicolumn{2}{|c|}{$\begin{array}{l}\text { TOTAL DE IES } \\
\text { QUE RESPONDEU }\end{array}$} \\
\hline 40 & $100 \%$ & 21 & $52,5 \%$ & 29 & $72,5 \%$ & 32 & $80 \%$ \\
\hline
\end{tabular}

Fonte: Autoria própria

O universo de subordinados pesquisados foi composto por cento e sessenta e nove pessoas (quarenta secretárias acadêmicas e cento e vinte e nove coordenadores de curso). Do total de cento e sessenta e nove pessoas obteve-se um retorno de quarenta e três subordinados, perfazendo $25,44 \%$.

\subsection{Resultados obtidos sobre o perfil das IES pesquisadas}

Observou-se, no universo pesquisado, que 50\% das IES respondentes possuem de cem a quinhentos alunos, apenas $18 \%$ possuem mais do que dois mil alunos e $16 \%$ ficam na posição intermediária, de um a dois mil alunos. Portanto conclui-se que a maioria das IES pesquisadas é composta por pequenas instituições. Ressalta-se que as instituições com até mil alunos representam $66 \%$ do total, sendo um número semelhante ao observado no censo da educação superior brasileira de 2003, em que instituições com até mil matrículas representavam 68,2\% do setor (BRASIL, 2004).

Outro dado importante levantado no site do INEP - Instituto Nacional de Pesquisas Educacionais é que $50 \%$ das IES pesquisadas tiveram seu ato legal de credenciamento a partir de 2001, ou seja, vinte instituições possuem cinco anos de idade ou menos de funcionamento. Destas, oito foram credenciadas nos anos de 2004 e 2005, representando $20 \%$ do total, sendo que a maior concentração está no número de IES que possuem de um a três cursos de graduação, totalizando $42,5 \%$ do total.

Outra questão relacionada ao perfil das IES pesquisadas é referente ao processo de escolha do dirigente principal na instituição. Conforme demonstrado no gráfico 1, 88\% dos pesquisados responderam que o dirigente principal é escolhido pela mantenedora da instituição, $6 \%$ que é eleito pelo Conselho Acadêmico Superior - CAS e em 6\% das IES pesquisadas há um outro meio de escolha do Diretor Geral, podendo ser uma eleição realizada entre os membros da mantenedora ou pelo corpo docente da instituição. Portanto, a maioria dos dirigentes principais ocupam cargos de confiança e podem ser dispensados a qualquer momento pelos mantenedores. 
Gráfico 1 - Processo de escolha do dirigente principal da IES

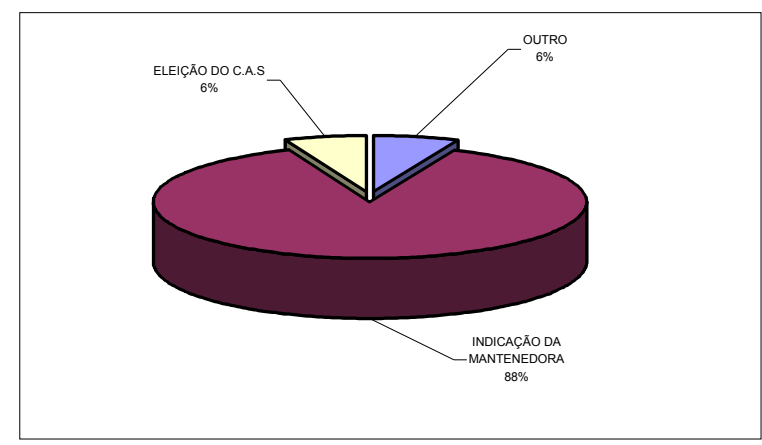

Fonte: Pesquisa de campo

\subsection{Resultados obtidos sobre o perfil do gestor da IES}

A média de permanência do tempo de cargo dos gestores principais das IES pesquisadas é de 3,71 anos. Dos vinte e um gestores pesquisados $24 \%$ estão no cargo há um ano ou menos, $38 \%$ ocupam o cargo de dois a quatro anos e o mesmo percentual, 38\% estão no cargo há mais de 6 anos, de acordo com o gráfico 2.

Gráfico 2 - Tempo de permanência no cargo dos gestores principais

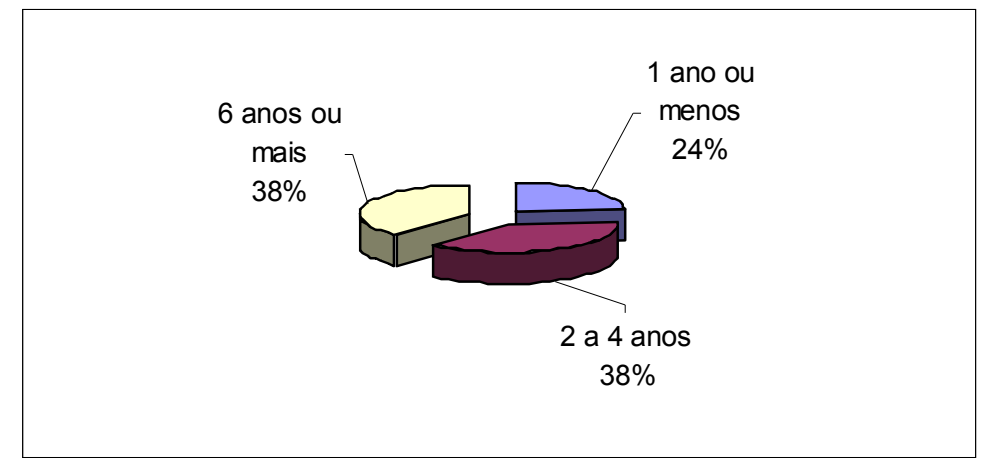

Fonte: Pesquisa de campo

Procurou-se determinar a época de ingresso do gestor na IES, mesmo antes de ocupar o cargo de dirigente principal. É interessante notar que a média do tempo de casa aumenta para 5,43 anos em relação à média do tempo no cargo que é de 3,71 anos. Outro ponto importante é que a maioria, ou seja, $62 \%$ dos gestores estão na IES há sete anos ou mais, demonstrando que muitos deles ocupavam outros cargos na instituição antes de chegar ao cargo principal - Tabela 2.

Das instituições pesquisadas, o gestor mais idoso possui 66 anos de idade e o mais novo está com apenas vinte e sete anos de idade. A média de idade das IES pesquisadas ficou em quarenta e seis anos. 
Tabela 2 - Tempo que o gestor principal da IES ocupa o cargo atual

\begin{tabular}{c|c|c}
\hline $\begin{array}{c}\text { TEMPO DO GESTOR } \\
\text { NA IES }\end{array}$ & NÚMERO DE IES & $\begin{array}{c}\text { \% DE IES EM RELAÇ̃̃O } \\
\text { TEMPO DE CASA DO GESTOR }\end{array}$ \\
\hline \hline Menos de 1 ano & 1 & $4,7 \%$ \\
\hline 1 ano & 0 & $0 \%$ \\
\hline 2 anos & 2 & $9,5 \%$ \\
\hline 3 anos & 3 & $14,3 \%$ \\
\hline 4 anos & 1 & 4,7 \\
\hline 5 anos & 0 & $0 \%$ \\
\hline 6 anos & 1 & $4,7 \%$ \\
\hline 7 anos ou mais & 13 & $62 \%$ \\
\hline TOTAL DE IES & 21 & $100 \%$ \\
\hline \hline Fonte: Pesquisa de campo & &
\end{tabular}

Com relação ao gênero, $76,2 \%$ dos dirigentes principais são do sexo masculino e apenas $23,8 \%$ pertencem ao sexo feminino. Todas as cinco mulheres que são dirigentes principais de IES trabalham em instituições que começaram a funcionar somente a partir do segundo semestre do ano de 2001, portanto instituições mais novas no mercado educacional.

Entre os dirigentes principais das IES existem de 10\% (2) de graduados, $24 \%$ (5) de especialistas, 47\% (10) de mestres e 19\% (4) de doutores, demonstrando que a maior concentração está no título de mestre.

Levantou-se que 10\% (2) dos gestores têm formação em Ciências Biológicas/Agrárias, 14\% (3) em Ciências Exatas e da Terra, 38\% (8) em Ciências Humanas e também 38\% (8) em Ciências Sociais e Aplicadas, evidenciando que a maioria dos dirigentes, 76\% (16) vêm das Ciências Humanas ou Sociais Aplicadas.

De acordo com o gráfico 3, as áreas que apresentam o maior número de gestores são Direito e Administração, com quatro gestores em cada uma delas; seguido de Engenharia, com três gestores; Economia, Educação e Letras, com dois gestores cada uma; e por último Farmácia, Agronomia, Psicologia e Teologia, com um gestor principal em cada uma delas. Pode-se observar que 52,4\% (11) dos Dirigentes principais das IES são procedentes dos cursos de Direito, Administração e Engenharia. 
Gráfico 3 - Área específica de formação dos gestores principais das ies

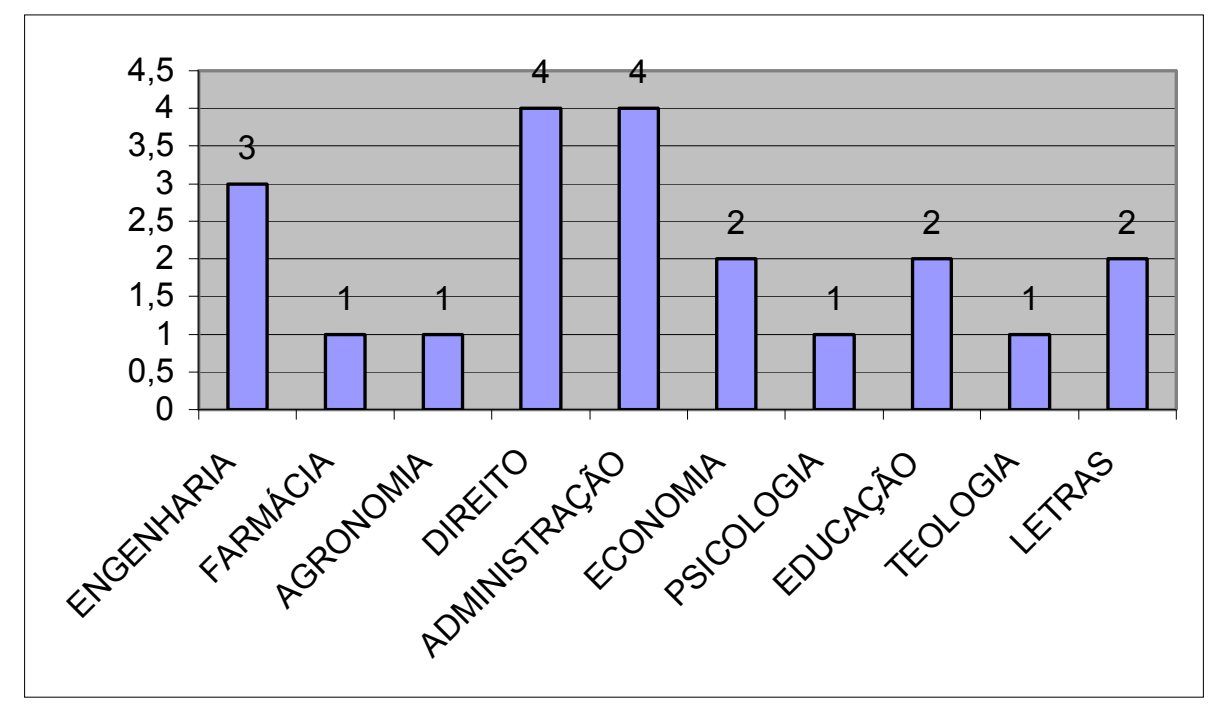

Fonte: Pesquisa de campo

Foi indagado, ainda, se o dirigente principal trabalhou como docente na IES antes de ocupar o cargo atual. É possível verificar nos resultados pesquisados que 52\% (11) trabalhou como professor antes de se tornar diretor e 48\% (10) não foi docente na IES.

A última questão, referente ao perfil do dirigente principal da IES, objetiva saber há quantos anos o diretor principal é professor no ensino superior ou se ele nunca foi docente. Observou-se que 24\% (5) dos diretores nunca foram professores, 14\% (3) são professores de um a quatro anos, 14\% (3) também são professores de 5 a 8 anos e $48 \%$ (10) são professores há mais de onze anos. Logo, se demonstra que existe uma grande experiência acadêmica como docente dos atuais dirigentes das IES.

\subsection{Grau de domínio das competências do gestor da IES}

Tendo em vista que um dos objetivos específicos deste trabalho é verificar o grau de domínio das principais competências dos gestores das Instituições de Ensino Superior privadas de Curitiba e Região Metropolitana, foram elaboradas, na segunda parte do questionário, vinte e duas questões para que o próprio dirigente principal da instituição respondesse e vinte para os seus subordinados, relacionadas às principais competências que um gestor de IES deve possuir. Este questionário foi colocado à disposição dos respondentes na Internet. Na figura 1 é demonstrada a tela de pesquisa com os dados a serem levantados para a segunda parte da pesquisa para os dirigentes. 
Figura 1 - Questionário aplicado aos gestores principais

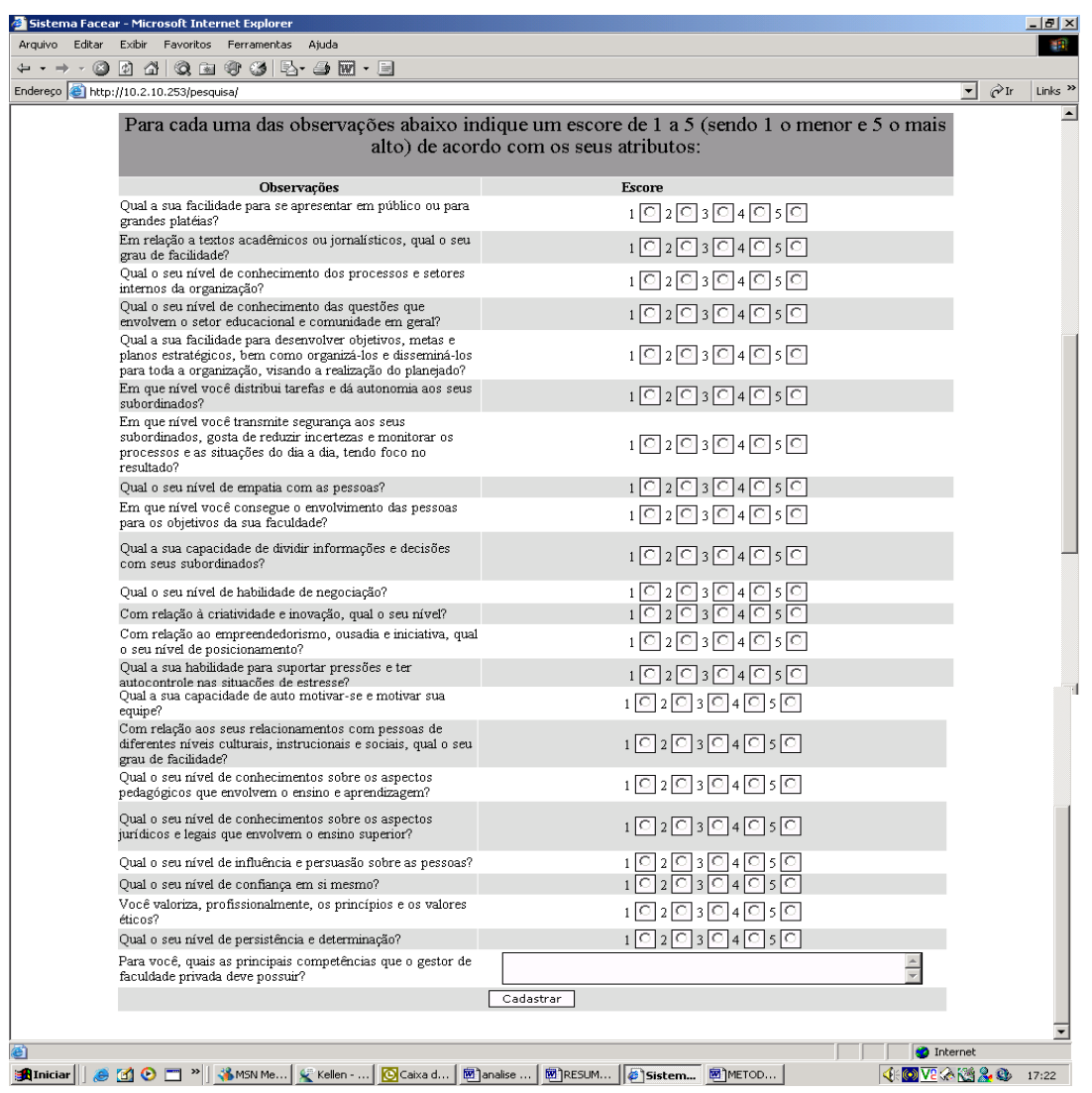

Fonte: Autoria própria

Conforme citado anteriormente, a segunda parte dos questionários dos dirigentes e seus subordinados foi diferente. Na pesquisa do dirigente havia perguntas relacionadas com a respectiva competência, já na pesquisa dos subordinados foi colocada a competência específica, uma explicação sobre ela, estas complementadas pelos escores de 1 a 5 . O objetivo de se aplicar o questionário para os dirigentes principais e para os subordinados diretos foi o de traçar um paralelo entre a auto-avaliação do dirigente e como os seus subordinados o avaliam, para que o grau de domínio das competências colocadas fosse o mais preciso possível.

Um resultado decorrente foi a ordem de prioridade atribuída às competências abordadas no questionário. Na tabela 3 é possível verificar a ordem decrescente de avaliação das competências do diretor, conforme sua própria opinião e também de acordo com o conceito atribuído pelos subordinados.

Os diretores e os subordinados avaliaram que as competências integridade e persistência são aquelas que os diretores têm o melhor grau de domínio, como pode ser observado na Tabela 3 . Subordinados e diretores também concordam quanto às competências que eles consideram mais fracas no dirigente principal, que são Planejamento Estratégico e Organização e Conhecimentos 
Jurídicos do Setor Educacional.

Tabela 3 - Notas de cada competência atribuída pelos diretores e subordinados em ordem decrescente.

\begin{tabular}{|c|c|c|c|}
\hline \multirow{3}{*}{$\begin{array}{lcc}\text { COMPETÊNCIAS } & \text { DO } & \text { DIRETOR } \\
\text { CONFORME A SUA PRÓPRIA OPINIÃO }\end{array}$} & \multicolumn{2}{|r|}{$\begin{array}{lll}\text { COMPETENNCIAS } & \text { DO } & \text { DIRETOR } \\
\end{array}$} & \multirow{3}{*}{$\begin{array}{l}\text { NOTA } \\
\text { TOTAL }\end{array}$} \\
\hline & NOTA & CONFORME A OPINIÃO DOS & \\
\hline & TOTAL & SUBORDINADOS & \\
\hline 1ª INTEGRIDADE $^{\text {a }}$ & 87,0 & 1 $^{\mathrm{a}}$ INTEGRIDADE & 82,0 \\
\hline $2^{\mathrm{a}}$ PERSISTÊNCIA & 85,0 & $2^{\mathrm{a}}$ PERSISTENCIA & 82,0 \\
\hline $3^{\text {a }}$ CONHECIMENTO SIST. INTERNO & 83,0 & $3^{\mathrm{a}}$ AUTO CONFIANÇA & 75,3 \\
\hline $4^{\mathrm{a}}$ RELACIONAM. INTER PESSOAIS & 79,0 & $4^{\mathrm{a}} \mathrm{MOTIVAÇÃO}$ & 75,0 \\
\hline $5^{\mathrm{a}}$ AUTO CONFIANÇA & 79,0 & $5^{\mathrm{a}}$ CONHECIMENTO SIST. EXTERNO & 73,0 \\
\hline $6^{\mathrm{a}}$ HABILID. SUPORTAR PRESSÕES & 78,0 & 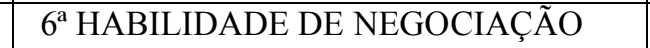 & 72,8 \\
\hline $7^{\mathrm{a}}$ CONHECIMENTO SIST. EXTERNO & 78,0 & $7^{\mathrm{a}}$ RELACIONAM. INTER PESSOAIS & 72,7 \\
\hline $8^{\mathrm{a}}$ MOTIVAÇÃO & 76,0 & $8^{\text {a }}$ HABILID. SUPORTAR PRESSÕES & 71,7 \\
\hline 9a CONTROLE ADMINISTRATIVO & 75,0 & $9^{a}$ INICIATIVA & 71,5 \\
\hline $10^{\mathrm{a}}$ PODER DE PERSUASÃO & 73,0 & $10^{\mathrm{a}}$ CONHECIMENTO SIST. INTERNO & 71,3 \\
\hline $11^{\mathrm{a}} \mathrm{HABILIDADE}$ DE NEGOCIAÇÃO & 73,0 & $11^{\mathrm{a}}$ LIDERANÇA & 70,8 \\
\hline 12a COMUNIC. E APRESENT. ORAL & 72,0 & $12^{\mathrm{a}}$ PODER DE PERSUASÃO & 70,3 \\
\hline $13^{\mathrm{a}}$ INICIATIVA & 70,0 & $13^{\mathrm{a}}$ DELEGAÇÃO & 70,3 \\
\hline 14 ${ }^{\mathrm{a}}$ CRIATIVIDADE E INOVAÇÃO & 69,0 & 14 ${ }^{\mathrm{a}}$ CRIATIVIDADE E INOVAÇÃO & 70,0 \\
\hline $15^{\mathrm{a} C O N H E C I M E N T O S ~ P E D A G O ́ G I C O S ~}$ & 68,0 & 15 $5^{\mathrm{a}}$ COMUNIC. E APRESENT. ORAL & 69,8 \\
\hline $16^{\mathrm{a}}$ LIDERANÇA & 67,0 & $16^{\mathrm{a}} \mathrm{CONHECIMENTOS} \mathrm{PEDAGÓGICOS}$ & 67,5 \\
\hline $17^{\mathrm{a}}$ DELEGAÇÃO & 67,0 & $17^{\mathrm{a}}$ CONTROLE ADMINISTRATIVO & 64,7 \\
\hline $18^{\text {a }}$ PLAN. ESTRATÉGICO E ORGAN. & 66,0 & $18^{\mathrm{a}}$ PLAN. ESTRATÉGICO E ORGAN. & 63,3 \\
\hline 19ª CONHEC. JURÍDICOS EDUCAC. & 65,0 & 19a CONHEC. JURÍDICOS EDUCAC. & 62,0 \\
\hline
\end{tabular}

Fonte: Pesquisa de campo

Apesar da variação existente entre a percepção do diretor e do subordinado, percebe-se que nas competências comunicação e apresentação oral, habilidades de negociação, criatividade, iniciativa, motivação e conhecimentos pedagógicos existe uma concordância maior nas avaliações. Já nas competências delegação e liderança os subordinados concederam notas melhores do que os próprios diretores. 
Gráfico 4 - Somatória das notas de cada competência atribuída por diretores e subordinados

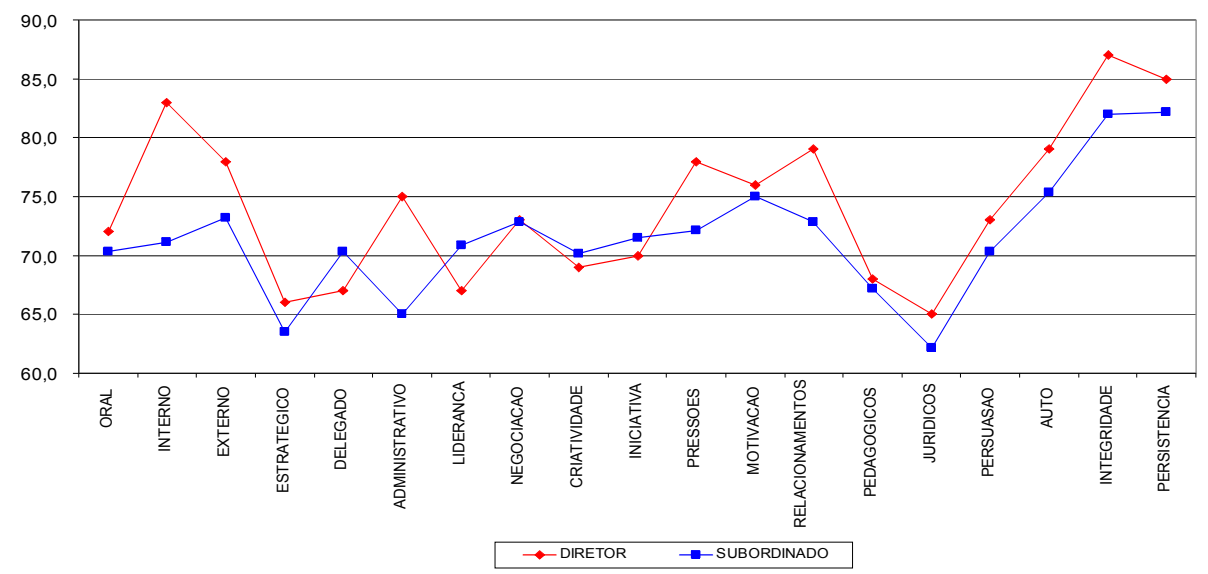

Fonte: Pesquisa de campo

Nas competências conhecimento sistêmico interno e externo, planejamento estratégico, controle administrativo, habilidade de suportar pressões, relacionamentos interpessoais, conhecimentos jurídicos do setor educacional, poder de persuasão, auto confiança, integridade e persistência, entretanto, o gestor foi mais indulgente.

Considerando-se as dezenove competências consideradas com maior pontuação como aquelas de excelência, capazes de se configurar como benchmark, foi possível levantar as competências que mais se aproximam deste grau de excelência e aquelas que ficam mais distantes deste nível ideal - ver Gráfico 5.

Gráfico 5 - Grau de excelência para cada competência

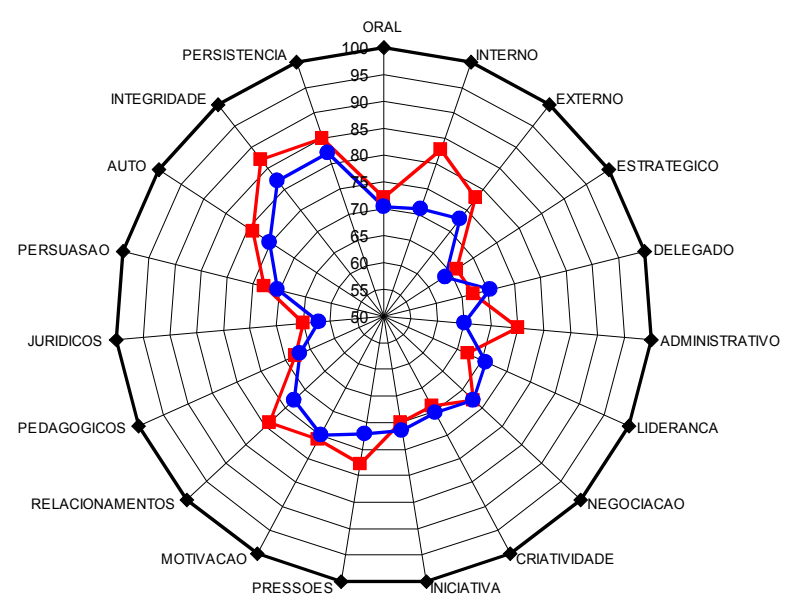

Fonte: Pesquisa de campo

\subsection{Principais competências do gestor para os respondentes}


Nos questionários realizou-se uma pergunta aberta indagando quais as principais competências que o gestor de uma instituição de ensino superior privada deve possuir. Segundo os respondentes, a competência mais importante para o gestor é a liderança, a habilidade mais citada por eles $-80 \%$ dos casos. Depois de liderança, a aptidão que os pesquisados mais mencionaram foi conhecimento sistêmico interno e externo, ou seja, a ciência que o gestor possui dos processos e setores internos da organização e das questões que envolvem o setor educacional como um todo. Foram $70 \%$ de menções neste sentido.

A integridade do gestor, colocando que este deve ser ético, honesto, leal, íntegro, moral, possuir caráter e seriedade, foi lembrada por $60 \%$ dos respondentes, que apontaram que um, ou mais, destes atributos são comportamentos ou atitudes importantes em um bom gestor. A importância de o gestor possuir habilidade para planejar estrategicamente foi registrada em $45 \%$ das respostas como sendo algo indispensável.

Foram reportadas entre quatro a oito vezes as seguintes competências: iniciativa, conhecimentos jurídicos do setor educacional, controle administrativo, relacionamentos interpessoais, conhecimentos pedagógicos e persistência. Com duas a três citações aparecem as competências de comunicação, delegação, criatividade, habilidades de negociação, habilidade de suportar pressões e poder de persuasão.

Todas as competências citadas estavam elencadas no questionário que os gestores e os subordinados responderam. Como a última questão foi aberta, muitos respondentes incluíram outras competências que seriam necessárias para um bom gestor. As que mais aparecem foram: flexibilidade, saber trabalhar em equipe, paciência e comprometimento.

Tanto os diretores como os subordinados, no computo geral, avaliaram que as competências integridade e persistência são aquelas que os diretores têm o melhor nível. Subordinados e diretores também concordam quanto às competências que eles consideram mais fracas no dirigente principal: planejamento estratégico, organização e conhecimentos jurídicos do setor educacional. Salienta-se que autores como Rocha e Granemann (2003), Tachisawa e Andrade (2002), Kotler e Fox (1994) destacam a importância do planejamento estratégico para a gestão moderna e eficiente e que o gestor precisa possuir competência para realizar, junto com o seu corpo técnico, o planejamento da instituição, com vistas a dirigir a organização em busca de metas e objetivos estratégicos.

De outra parte, a educação superior no Brasil é um dos setores produtivos mais regulamentados pelo governo. Por esta razão, é de fundamental importância que o gestor tenha conhecimentos jurídicos do setor educacional, pois a cada dia são editadas leis, portarias, decretos, resoluções, pareceres, que interferem diretamente na IES.

A integridade apareceu no topo das competências melhores avaliadas, tanto pelos gestores 
como pelos subordinados. Quando foi colocada esta competência no questionário não havia dúvida que ela é essencial para o gestor e que na auto-avaliação do gestor ela seria muito bem pontuada. Contudo, o objetivo era saber qual a opinião do subordinado sobre a integridade do seu diretor e, de modo geral, os gestores foram muito bem avaliados neste quesito, mas, ainda assim, 9\% dos subordinados pesquisados deram nota um ou dois para o seu dirigente, considerando-o como péssimo ou ruim, respectivamente.

Diante do exposto, elaborou-se um quadro conclusivo - Quadro 1, com as competências propostas no referencial teórico desta pesquisa, as competências consideradas mais importantes pelos respondentes, aquelas elencadas no questionário envolvendo o grau de domínio, resultando nas competências requeridas pelo gestor de IES privada para ser eficiente e eficaz no cargo em que ocupa, considerando-se o âmbito deste trabalho. Tal quadro configura-se como um mapeamento de competências requeridas pelos gestores em foco. 
Quadro 1 - Competências requeridas pelos gestores de ies privadas

\begin{tabular}{|c|c|}
\hline \multicolumn{2}{|c|}{ Competências citadas no Referencial Teórico } \\
\hline $\begin{array}{l}\text { Servir o cliente (Auxiliar pessoas, atender clientes, tomar as dores dos clientes, assumir } \\
\text { pessoalmente a resolução de seus problemas). }\end{array}$ & Sensibilidade organizacional \\
\hline $\begin{array}{l}\text { Conquistar (Apresentar comportamentos que variam desde realizar um bom trabalho até } \\
\text { cumprir as metas e costuma ser arrojado). }\end{array}$ & Sensibilidade extra organizacional \\
\hline Controlar (Segurança, reduzir incertezas, monitorar). & Análise (Utilizar o raciocínio de causa e efeito). \\
\hline $\begin{array}{l}\text { Foco em estratégias (Está relacionado ao cenário externo considerando as políticas, } \\
\text { economia, concorrências, cenários e tendências). }\end{array}$ & Julgamento (Avaliação, ponderação). \\
\hline Inovação (Procura caminhos ainda não percorridos, inventar e reinventar a roda). & Conceituação (Compara fatos, conceitos, faz inferências). \\
\hline Mudança (Luta por mudanças, sempre vendendo sua idéia). & Difusão (Compartilha conhecimentos). \\
\hline Colaboração (Coopera, participa, contribui positivamente). & Expertise (Domínio técnico). \\
\hline Comando (Faz a coisa acontecer). & Apresentação Oral \\
\hline Delegação (Dar poder às pessoas). & Comunicação Oral \\
\hline Desenvolvimento (Ensina, mostra como faz, treina). & Comunicação Escrita \\
\hline Desenvolvimento de subordinados & Consciência Organizacional \\
\hline Liderança (Procura dividir informações e decisões). & Consciência Extra Organizacional \\
\hline Persuasão (Influência). & Planejamento e Organização \\
\hline Manipulação (Usa o conhecimento da situação para conduzir as coisas). & Negociação \\
\hline Networking (Construindo redes de relacionamento). & Correr riscos \\
\hline Autoconfiança (Confiança em si mesmo). & Poder de decisão \\
\hline Autocontrole (Controle emocional). & Energia \\
\hline Criatividade (Testar novas alternativas de solução). & Tolerância ao stress \\
\hline Curiosidade (Buscar informações). & Adaptabilidade e resiliência \\
\hline Flexibilidade (Jogo de cintura, maleabilidade). & Motivação \\
\hline Iniciativa (Autopropulsão). & Condução de grupos \\
\hline Integridade (Agir conforme princípios e valores). & Auto aprendizado e auto desenvolvimento \\
\hline Persistência (Determinação). & Satisfação social \\
\hline Tenacidade (Obstinação, afinco). & Vivência no exterior \\
\hline Sensibilidade (Ter empatia, compreender os outros). & \\
\hline
\end{tabular}

\begin{tabular}{|c|}
\hline $\begin{array}{c}\text { Competências citadas na pesquisa } \\
\text { qualitativa }\end{array}$ \\
\hline Liderança \\
\hline Conhecimento sistêmico interno \\
\hline Conhecimento sistêmico externo \\
\hline Integridade \\
\hline Planejamento Estratégico \\
\hline Iniciativa \\
\hline Conhecimentos Jurídicos do setor Educacional \\
\hline Controle Administrativo \\
\hline Relacionamentos Inter pessoais \\
\hline Conhecimentos Pedagógicos \\
\hline Persistência \\
\hline Comunicação \\
\hline Delegação \\
\hline Criatividade \\
\hline Habilidades de Negociação \\
\hline Habilidade de Suportar Pressões \\
\hline Poder de Persuasão \\
\hline Flexibilidade \\
\hline Trabalho em equipe \\
\hline Paciência \\
\hline Comprometimento \\
\hline
\end{tabular}

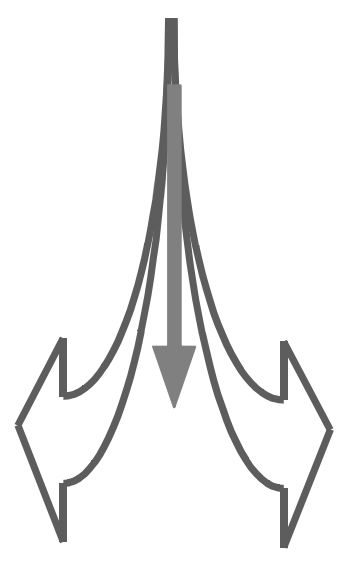

\begin{tabular}{|l|}
\hline \multicolumn{1}{|c|}{ Competências elencadas no grau de domínio } \\
\hline Integridade \\
\hline Persistência \\
\hline Auto confiança \\
\hline Motivação \\
\hline Conhecimento sistêmico Externo \\
\hline Habilidade de negociação \\
\hline Relacionamentos Inter pessoais \\
\hline Habilidade de Suportar pressões \\
\hline Iniciativa \\
\hline Conhecimento sistêmico Interno \\
\hline Liderança \\
\hline Poder de persuasão \\
\hline Delegação \\
\hline Criatividade e inovação \\
\hline Comunicação e Apresentação Oral \\
\hline Conhecimentos pedagógicos \\
\hline Controle administrativo \\
\hline Planejamento Estratégico e Organização \\
\hline Conhecimentos Jurídicos Educacionais \\
\hline
\end{tabular}

\begin{tabular}{|l|l|l|}
\hline \multicolumn{2}{|l|}{ Competências requeridas pelo gestor de IES privada. } \\
\hline Integridade & Iniciativa & Controle administrativo \\
\hline Persistência & Conhecimento sistêmico Interno & Planejamento Estratégico e Organização \\
\hline Auto confiança & Liderança & Conhecimentos Jurídicos Educacionais \\
\hline Motivação & Poder de persuasão & Flexibilidade, Adaptabilidade e Resiliência \\
\hline Conhecimento sistêmico Externo & Delegação & Comunicação Escrita \\
\hline Habilidade de negociação & Criatividade e inovação & Análise e Julgamento \\
\hline Relacionamentos Inter pessoais & Comunicação e Apresentação Oral & Saber trabalhar em equipe \\
\hline Habilidade de Suportar pressões & Conhecimentos pedagógicos & Vivência no exterior \\
\hline
\end{tabular}

Fonte: Autoria Própria 


\title{
4. Conclusões
}

Para Baldridge (1983) as instituições de ensino superior têm características especiais que as tornam uma organização complexa. Esta complexidade é decorrente de fatores externos e internos. Internos consideram-se seus objetivos difusos e ambíguos, sua tecnologia fragmentada, a presença de distintos grupos de interesse no seu interior, sua função de atender às necessidades específicas de seus clientes, do profissionalismo do trabalho acadêmico. Externos sua vulnerabilidade ao mercado.

Tendo em vista este contexto, buscou-se conhecer quais competências seriam mais importantes para ser um gestor de IES eficiente. Apesar de a pesquisa ter sido realizada em Curitiba e Região Metropolitana, é possível aplicar o mapeamento de competências proposto neste trabalho para outras IES privadas do Estado do Paraná e do Brasil, já que o cenário de expansão e concorrência também foi registrado nas outras regiões do país e o modelo de gestão é bastante parecido, com apenas algumas diferenças culturais de região para região.

Com o mapeamento proposto espera-se dar uma contribuição para as IES privadas, já que elas poderão saber quais competências são requeridas para um bom diretor e, a partir disso, recrutar e selecionar um gestor com estes conhecimentos, atitudes e habilidades.

\begin{abstract}
In the last decade the scenario of superior education in Brazil has been significantly altered, having affected ultimately the pre-existing institutions and the ones which have this segment. To face this reality it has become necessary to seek innovating management models to face these new times. The role of the principal of a superior education institution is fundamental to achieve a model of management that is efficient and adapted to this new scenario. This study has attempted to identify in the theoretical references which are the managers' main competencies, and has also outlined the profile of the managers of private institutions in Curitiba and in the neighboring districts. In addition, it has checked the managers' skill level concerning these competencies, and has also proposed which are the main competencies that a private Institution manager should have. The investigation was exploratory, bibliographical and descriptive, with characteristics of qualitative and quantitative research. The method survey was also used, which allowed a clear and precise elaboration of the determining system of cause and effect. The field research involved 40 private institutions of superior education in Curitiba and the neighboring districts. The collected data were presented according to the objectives proposed in the beginning of the study. The obtained conclusions have been quite interesting in identifying the current profile of the managers of the private institutions in Curitiba and the neighboring districts and also the main competencies necessary for a manager of a private institution to be efficient in performing his function
\end{abstract}

Keywords: superior education; management; manager; competencies; institutions of superior education. 


\section{Referências}

BALDRIDGE, J. V. et al. Organizational Characteristics of Colleges and Universities. In: J.V. Baldridge \& Del (editors). The Dynamics of Organizational Change in Education. Berkeley: McUtchan, 1983, p. 38-59.

BRASIL. Ministério da Educação. Censo da Educação Superior 2003, resumo técnico. Brasília, 2004.

DURAND, Thomaz. L'Alchimie de la Compétence. Revue Française de Gestion, Paris, n.127, p. 84-102, Jan-Fev / 2000.

KOTLER, P.; FOX, K. F. A. Marketing estratégico para Instituições Educacionais. São Paulo: Atlas, 1994.

MARCOVITCH, J. A Universidade (Im)possível. São Paulo: Futura, 1998.

TACHIZAWA, T.; ANDRADE, R. O. B. Gestão de Instituições de Ensino. Rio de Janeiro: Fundação Getúlio Vargas, 2002.

TRIVIÑOS, Augusto N. S. Introdução à pesquisa em Ciências Sociais. São Paulo: Atlas, 1995.

WOOD, T. J. Remuneração por Habilidades e Competências: preparando a organização para a era das empresas e do conhecimento intensivo. São Paulo: Atlas, 1997.

\section{Dados completos de todos os autores:}

Nome completo: Faimara R. Strauhs

Filiação institucional: UTFPR - Universidade Tecnológica Federal do Paraná

Departamento Acadêmico de Eletrotécnica

Função ou cargo ocupado: Professora

Laboratório de Inovação e Tecnologia em Sistemas Embarcados

Funçao ou cargo ocupado: Pesquisadora

Endereço completo para correspondência (bairro, cidade, estado, país e CEP): Av. Sete de Setembro, 3165, Curitiba, Paraná, CEP.: 80.230-901

Telefones para contato: $413310-4758$

e-mail: faimara@lit.citec.cefetpr.br

\section{Nome completo: Murilo Martins de Andrade}

Filiação institucional: Facear - Faculdade Educacional de Araucária

Departamento: Direção Geral

Função ou cargo ocupado: Diretor Geral

Endereço completo para correspondência (bairro, cidade, estado, país e CEP): Av. das Araucárias, 3803, Bairro Thomaz Coelho, Araucária, Paraná, Cep 83707-000

Telefones para contato: 4136431551

e-mail: murilo@facear.edu.br

Recebido para publicação em: 12/07/06

Aceito para publicação em: 14/09/06 